\title{
О СИНТЕЗЕ АЛКИЛПОЛИЭТОКСИЭТАНОЛОВ
}

Полигликолевые эфиры спиртов, кислот и аминов представляют интерес не только как неионогенные поверхностно-активные вещества (ПАВ), но и как промежуточные продукты синтеза новых ПАВ, обладающих специфическими свойствами. Поэтому представляет интерес всестороннее изучение методов синтеза полигликолевых эфиров первичных и вторичных спиртов, их карбоксилированных производных и коллонднохимических свойств промежуточных и конечных продуктов.

В результате оксиэтилирования высших спиртов при получении неионогенных ПАВ образуется сложная смесь полимергомологов с общей формулой $\mathrm{R}\left(\mathrm{OCH}_{2} \mathrm{CH}_{2}\right)_{n} \mathrm{OH}$, где количество присоединенных молей окиси этилена можно характеризовать только среднестатистическими методами, например, по формуле Флори-Пуассона [1].

Для получения сравнительных данных о свойствах ПАВ необходимо иметь достоверные результаты не только о распределении полимергомологов, но и о составе и свойствах индивидуальных алкилполиэтоксиэтанолов с заданным числом оксиэтильных групп. Однако о свойствах индивидуальных алкоксиэтанолов, в частности об их поверхностноактивных свойствах, имеется сравнительно мало сведений. Поэтому представляет интерес получение индивидуальных соединений с общей формулой $\mathrm{R}\left(\mathrm{OCH}_{2} \mathrm{CH}_{2}\right)_{n} \mathrm{OH}$, а также аналогичных продуктов обычным оксиэтилированием высших спиртов. По полученным таким образом сравнительным результатам, можно достоверно судить о возможностях и целесообразности применения тех или иных методов в препаративных и промышленных условиях.

Цель данной работы - получение ряда гексаэтиленгликолевых эфиров высших спиртов как методом Вильямсона, так и оксиэтилированием их в присутствии щелочи, принятым в промышленности.

\section{Экспериментальная часть}

Синтез полиэтоксиалканолов методом Вильямсона осуществляли по схеме:

$$
\mathrm{RX}+\mathrm{Na}\left(\mathrm{OCH}_{2} \mathrm{CH}_{2}\right)_{6} \mathrm{OH} \rightarrow \mathrm{NaX}+\mathrm{R}\left(\mathrm{OCH}_{2} \mathrm{CH}_{2}\right)_{6} \mathrm{OH},
$$

где галогеном $(\mathrm{X})$ служили бром или иод. Все исходные бромиды и гексаоксиэтиленгликоль синтезированы в лабораторных условиях: бромиды - путем бромирования соответствующих спиртов с $48 \%$-ным раствором $\mathrm{HBr}\left[{ }^{2}\right]$, гексаоксиэтиленгликоль - по методике Фордиса и др. [ $\left.{ }^{3}\right]$ из дноксиэтиленгликоля и $\beta, \beta^{\prime}$-дихлорэтилового эфира (хлорекса). 


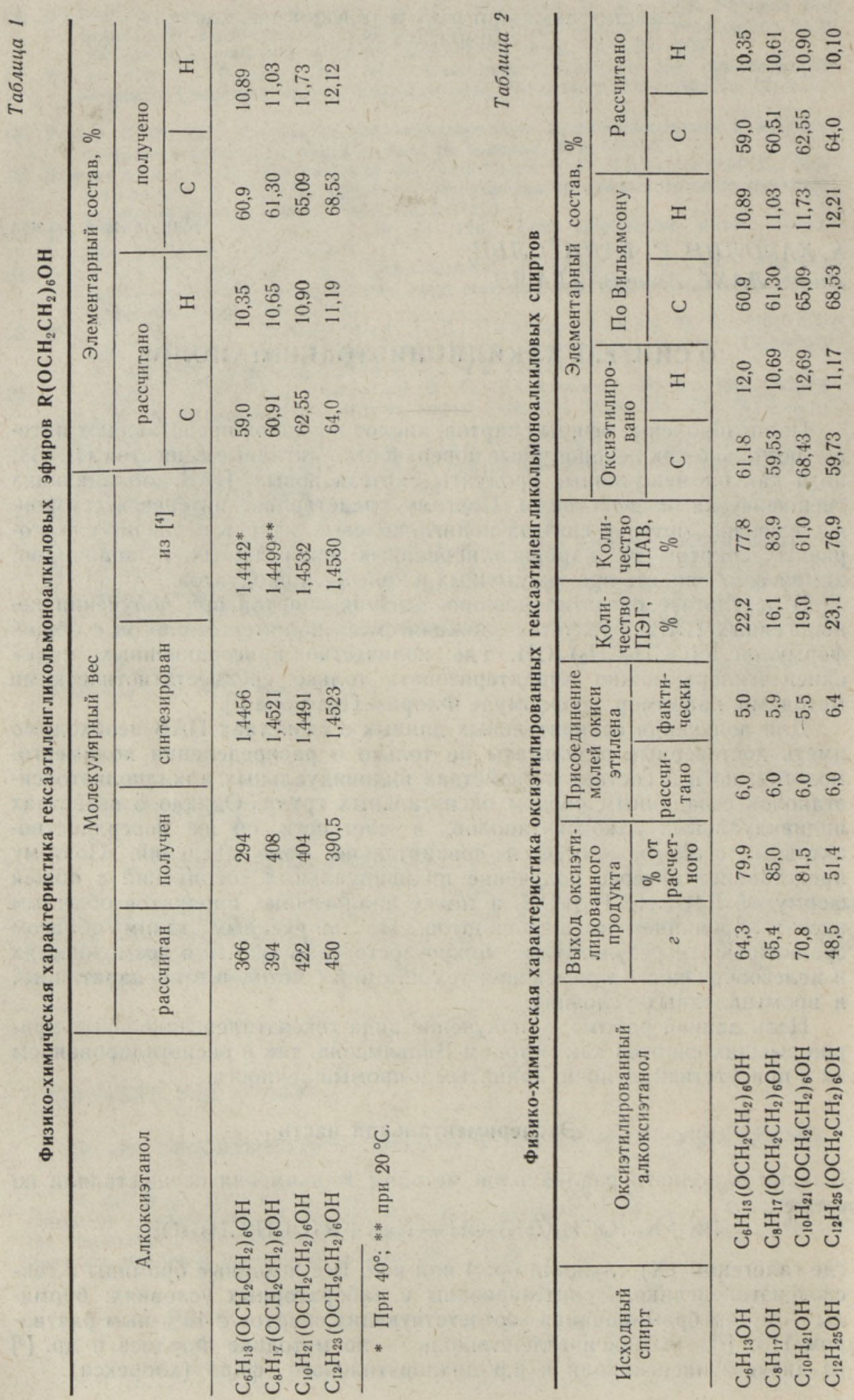


Синтез гексаоксиалканолов осуществляли по модернизированной в сравнении с описанной в литературе [5] методике. В 100 мл метанола растворяли 6 г $(0,25$ г-атома) металлического натрия, и смесь нагревали при $70^{\circ} \mathrm{C}$ в течение часа, после чего добавляли 71 г (0,25 моля) гексаэтиленгликоля и нагревали при $80^{\circ}$ в течение 3 ч. После удаления из реакционной смеси метанола температуру реакции повышали до $100^{\circ}$ и в реакционную смесь добавляли 0,25 моля соответствующего алкилбромида. Реакционную смесь нагревали при $120-130^{\circ}$ в течение 8 . После отделения осадка фильтрат экстрагировали этиловым эфиром. Определены физико-химические характеристики полученных в результате трехкратной очистки эфиром и этанолом продуктов (табл. 1).

Оксиэтилирование спиртов проводилось в автоклаве. Измерение и дозировку окиси этилена осуществляли в специальном мернике-испарителе, который был связан непосредственно с баллоном окиси этилена.

В реактор загружали реакционную смесь (спирт и катализатор сухой $\mathrm{KOH}$ в количестве $1-2 \%$ от веса спирта), затем до начала реакции из мерника подавали некоторое количество $(2-3$ г) окиси этнлена. Как правило, реакция начиналась после подачи 1,5-2 г его, что приводило к повышению давления до 2-3 атм.

При таком режиме оксиэтилирования и температуре $125-135^{\circ} \mathrm{K}$ исходному спирту присоединяли расчетное количество (6 молей) окиси этилена.

После введения расчетного количества окиси этилена реакционную смесь перемешивали до тех пор, пока давление в реакторе не понижалось до исходного. По окончании реакции продукт нейтрализовали ледяной уксусной кислотой.

Синтезированные оксиэтилированные спирты - неионогенные ПАВ (прозрачные гомогенные жидкости от светло-желтого до темно-красного цвета) были растворимыми в воде, эфире, этаноле, бензоле и толуоле. Физико-химический анализ приведен в табл. 2.

\section{Обсуждение результатов}

Результаты физико-химического анализа алкоксиэтанолов свидетельствуют о том, что выбранные условия синтеза позволяют получить неионогенные ПАВ с удовлетворительными выходами и с достаточной чистотой. Синтез полигликолевых эфиров по Вильямсону сопровождается образованием побочных продуктов в виде примесей ненасыщенного, диэфирного и сложноэфирного характера. Об этом свидетельствуют инфракрасные спектры полученных алкоксиэтанолов (рис. 1), которые показывают во всех случаях возможность присутствия карбонильных, а также сложноэфирных групп (при частотах поглощения 1730 и $1625\left(\boldsymbol{s}^{-1}\right)$, обусловленных, вероятно, наличием в продуктах натриевых солей $\mathrm{R}-\mathrm{C}-\mathrm{ONa}$. Образование непредельных соединений в продуктах<smiles>[CH]1C=C1</smiles>

\section{реакции минимально.}

Результаты элементарного анализа хорошо совпадают с расчетными данными в случае алкоксиэтанолов с гексиловым и октиловым радикалами, и незначительно различаются в случае продуктов с дециловым и додециловым радикалами. Показатели преломления определяли при $25^{\circ}$. Поскольку в литературе [4] значения индексов рефракции при разных температурах и значения показателей преломления различны, то на основе их трудно судить о чистоте полученных продуктов. В то же 

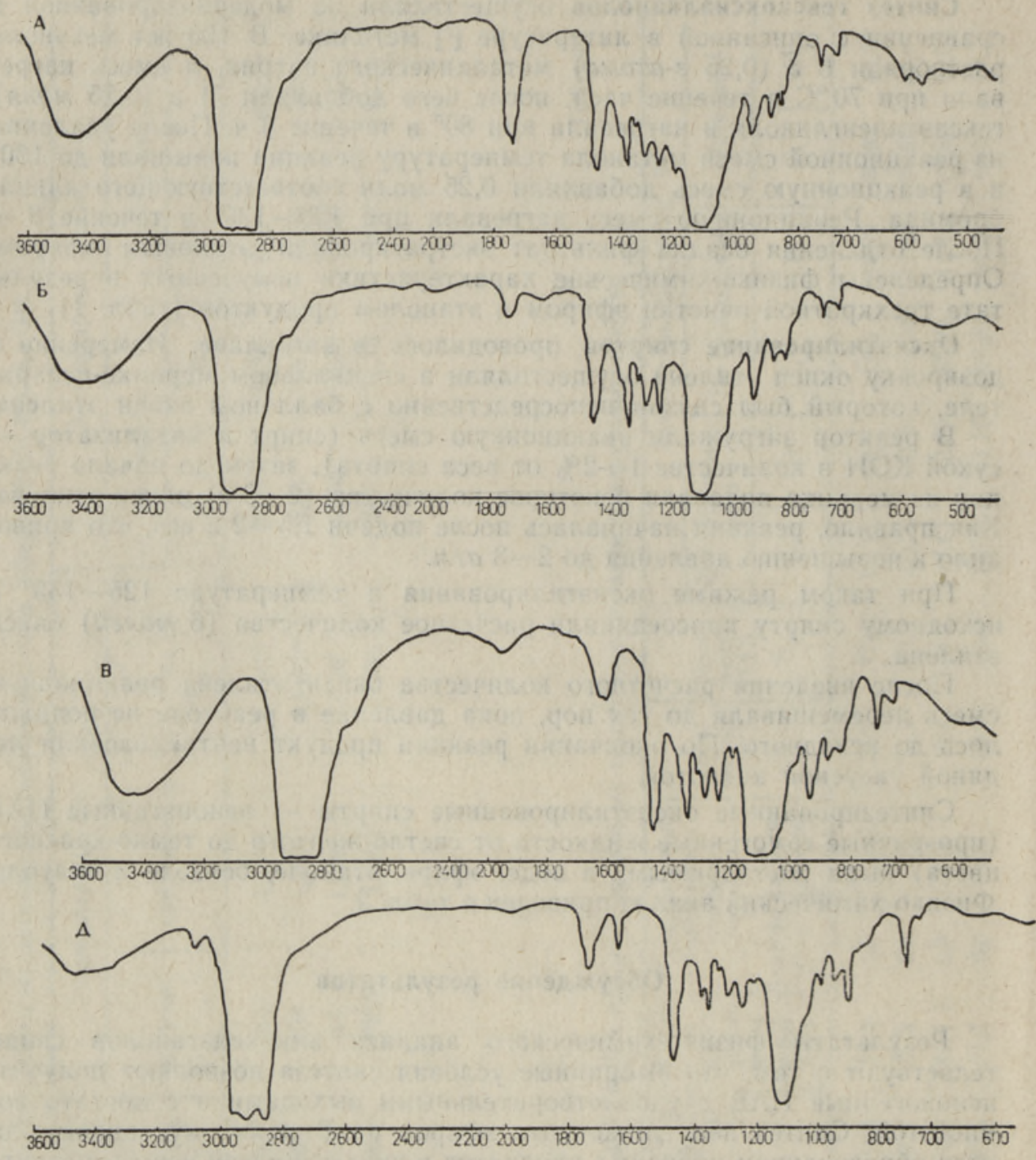

Рис. 1. ИК-спектры гекса- $(A)$, окта- $(Б)$, дека- $(B)$ и додекапентаэтоксиэтанола ‘Д).

время показатели, определенные при аналогичных температурах, хорошо совпадают.

Кроме алкоксиэтанолов, которые были выделены из реакционной смеси в виде эфиров, в результате синтеза образовались также эфиронерастворимые продукты, которые хорошо растворялись в воде и этиловом спирте. Они не гомогенны и представляют собой вязкую жидкость и кристаллический осадок. Физико-химический анализ показал, что спирторастворимая часть продуктов в основном состоит из непрореагировавших полигликолей, а осадок - из диэфиров и высокополимерных соединений. Все изложенное выше относится и к оксиэтилированным алкилполиэтоксиэтанолам.

Проведенные исследования показывают, что о чистоте и о количестве действительно присоединенных молей окиси этилена можно судить только с помощью среднестатистических методов. 

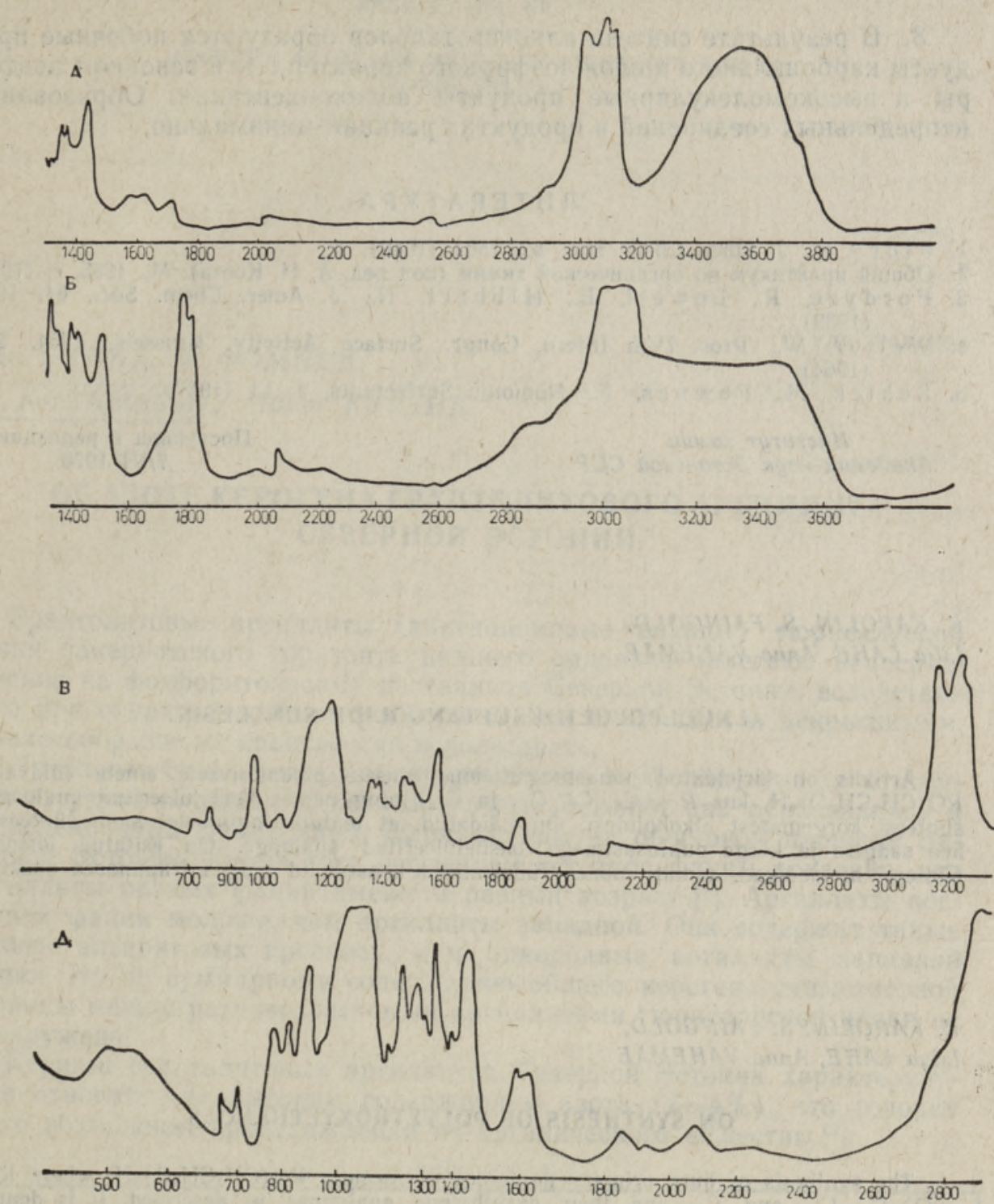

Рис. 2. ИК-спектры оксиэтилированных гекса- $(A)$, окта- $($ D), дека- $(B)$ и додекапентаэтоксиэтанола (Д).

\section{Выводы}

1. Методом Вильямсона синтезированы гексапентаэтоксиэтанол, октапентаэтоксиэтанол, декапентаэтоксиэтанол и додекапентаэтоксиэтанол с достаточно хорошими выходами $(45-60 \%)$ и хорошей степенью чистоты. Для получения совершенно чистых препаратов необходима дополнительная очистка хроматографическим методом.

2. В результате оксиэтилирования гексилового, октилового, децилового и додецилового спиртов можно также получить неионогенные ПАВ с высокими выходами и после извлечения полигликоля - с достаточной степенью чистоты. 
3. В результате синтеза алкоксиэтанолов образуются побочные продукты карбонильного и сложноэфирного характера - в основном диэфиры и высокомолекулярные продукты поликонденсации. Образование непредельных соединений в продуктах реакции минимально.

\section{ЛИТЕРАТ У РА}

1. F1 o r y, P., J. Amer. Chem. Soc., 62, 1561 (1940).

2. Общий практикум по органической химии (под ред. А. Н. Коста), М., 1965, с. 170.

3. Fordyce, R., Lowe11, E., Hibbert, H., J. Amer. Chem. Soc., 61, 1905 (1939).

4. Welle r, W., Proc. IVth Intern. Congr. Surface Activity. Brussels, 1964, 241 (1964).

5. Schick, M., Fownes, F., Nonionic Surfactants, 2, 13 (1967).

Институт химии

Академии наук Эстонской ССР
Поступила в редакцию 7/VI 1976

K. KAROLIN, S. FAINGOLD,

Lilja LAHE, Anne VAHEMÄE

\section{ALKUOLPOLUETOKSUETANOOLIDE SUNTEESIST}

Artiklis on kirjeldatud puhaste mitteionogeensete pindaktiivsete ainete (üldvalem $\mathrm{RO}\left(\mathrm{CH}_{2} \mathrm{CH}_{2} \mathrm{O}\right)_{6} \mathrm{H}$, kus $R=\mathrm{C}_{6}, \mathrm{C}_{8}, \mathrm{C}_{10}$ ja $\left.\mathrm{C}_{12}\right)$ ning nende oksüetüleeritud analoogide sünteesi kõrgematest alkoholidest. On näidatud, et teatud tingimustel saab sünteesida hea saagise ja kõrge puhtusastmega oksüetüleeritud analooge. On esitatud ühendite sünteesi metoodikad, samuti mōned füüsikalised konstandid ning infrapunased spektrid.

K. KAROLIN, S. FAINGOLD,

Lilya LAHE, Anne VAHEMAE

\section{ON SYNTHESIS OF POLYETHOXYETHANOLS}

The synthesis of pure primary nonionics of formula $\mathrm{RO}\left(\mathrm{CH}_{2} \mathrm{CH}_{2} \mathrm{O}\right)_{6} \mathrm{H}$, where $\mathrm{R}=$ $=\mathrm{C}_{6}, \mathrm{C}_{8}, \mathrm{C}_{10}$ and $\mathrm{C}_{12}$ and their oxyethylene analogues is described. It is demonstrated that under certain conditions oxyethylated compounds may be synthesized in good yields and high purity, like the primary ones. The preparative technique, some physical constants and the infrared spectrum of the nonionics are discussed. 